\title{
The sustainable dwelling development of human settlement on Orchid Island
}

\author{
S.-T. Kuo ${ }^{1} \&$ C.-J. Chen ${ }^{2}$ \\ ${ }^{1}$ Research Assistant, \\ Graduate Institute of Urban Development and Architecture, \\ National University of Kaohsiung, Taiwan \\ ${ }^{2}$ Associate Professor, \\ Graduate Institute of Urban Development and Architecture, \\ National University of Kaohsiung, Taiwan
}

\begin{abstract}
Orchid Island (Lan-Yu) is off Taiwan's southeastern coast. It is mostly populated by an aboriginal people called the Tao (or Yami). Three thousand people inhabit the island with a unique human settlement, living culture, society system and natural landscape, which are explicitly different from the main Taiwan Island.

For Orchid Island, in the past, the spatial change and environmental impact were inconspicuous. The Tao people remained the most primitive but sustainable of Taiwan's aboriginal community. Nowadays, when the traditional and indigenous culture, environment, and settlement are transformed by external culture, ecological invasion, and inappropriate policies; there is also rapid change of the characteristic living style and dwelling types. The traditional housing units seem in danger of extinction, replaced by government or self-built square concrete boxes. The old houses have nearly disappeared from several of the island's six villages.

The goals of this study are, firstly, to observe the evolution processes of human settlement and to compare the traditional spatial forms and the transformed ones. Secondly, a goal is to emphasize the former attitude and to propose a sustainable strategy for developing the dwelling type by respecting and adopting the traditional culture and historic apologue. The concrete tactics for construction and architectural concepts are proposed in this paper.
\end{abstract}

Keywords: Orchid Island, Tao people, human settlement, traditional dwelling. 


\section{Introduction}

Orchid Island (Lan-Yu) is off Taiwan's southeastern coast. It is mostly populated by an aboriginal people called the Tao. There are three thousand people inhabiting the island with a unique human settlement, living culture, society system and natural landscape, which are totally different from the other peoples of main Taiwan Island. Orchid Island is a volcanic island formed of magma erupting from the ocean floor. It was formerly known as "Redhead Island" because the peaks of the mountains at the northwestern corner of the island resemble red human heads in the crimson rays of the setting sun. The present appellation refers to the many wild orchids that once grew on this island. The humid, rainy climate has cloaked the mountainous interior of the island with a thick rain-forest cover, and has provided it with a large variety of ecosystems [1].

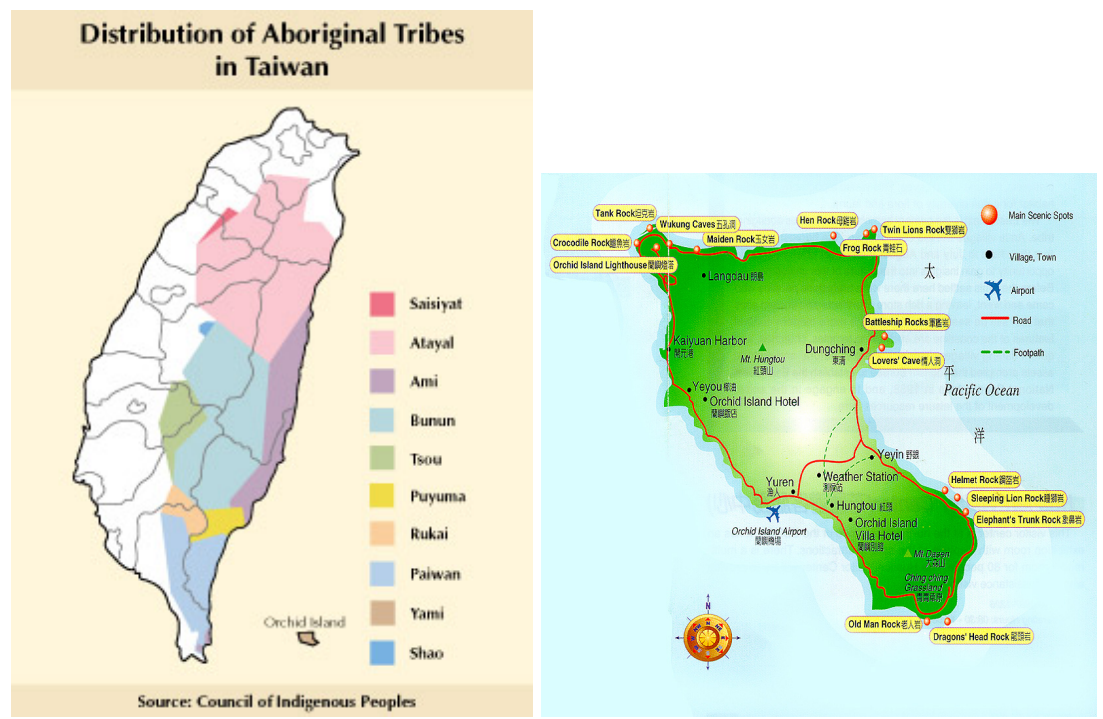

Figure 1: The distribution of aboriginal people (left) and the geographical description of Orchid Island (right) [1,4].

\subsection{Human settlement}

Orchid Island consists of six villages that are distributed around the coast of the island. They are Yayu Yeyou, Iraralay Langdau, Iranumilk Dongqing, Ivarinu Yeyin, Imourud Hongtou and Iratai Yuren. The typical configuration of a village is shown in Figure 2 [2]. All villages are situated near the port, and are ringed by the paddy field where taro is the primary crop for the Tao people. The shipyard, cemetery and desolation are arranged separately. The mountain and the forest provide a rich water resource and construction materials, respectively. 


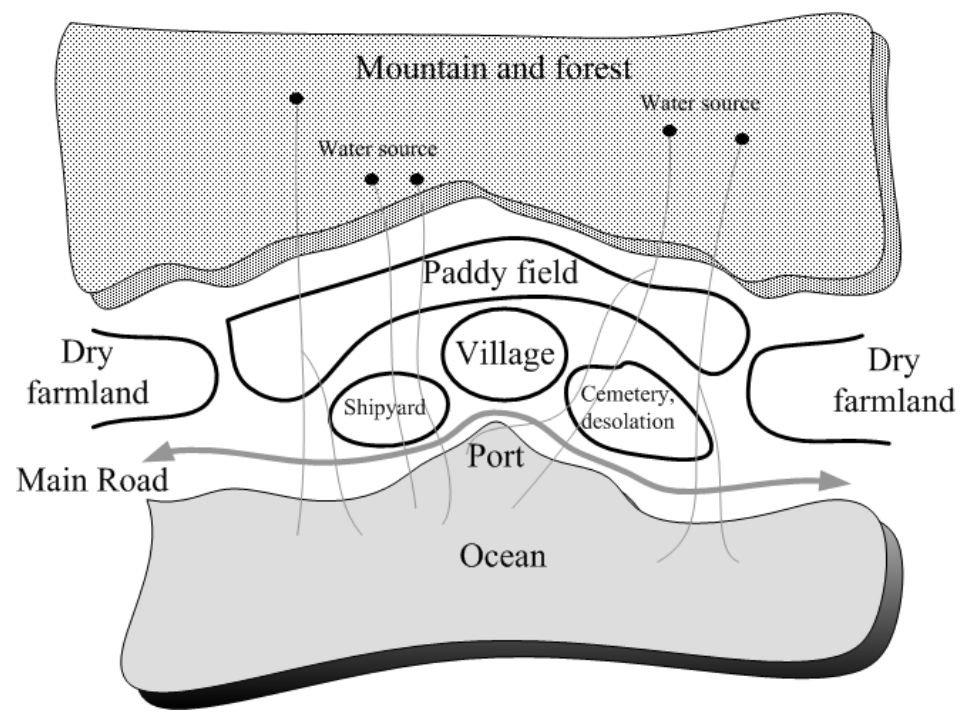

Figure 2: Composition of settlement in Orchid Island.

\subsection{Living culture}

The Tao people have always depended primarily on the sea for their livelihood, a fact which is reflected in their unique culture. The men wear narrow loincloths for convenience when fishing or hunting; they use richly decorated canoes, which are similar to what other Austronesian people use. Behind the construction of this well-crafted canoe are the symbols of social organization and the inheritance of the traditional culture that hold together the consciousness of the Tao people.

\subsection{Traditional dwellings}

The original Taos' dwellings were built partially underground and had a complex constitution. The traditional dwelling mainly consists of three elements as a unit: working house, platform, subterranean main house (Figure 3) that is dug into the earth as a spacious pit, so that the roof is nearly level with the surface of the surrounding earth. The boundary between houses is surrounded by cobbles in a natural way. The well designed drainage system doesn't cause flooding in the village. For Tao people, the subterranean house not only shelters their families against natural disasters, especially Typhoon during summer and torrid heat, but also symbolizes the vital tradition and social status of adult males in the tribe. The various sizes of dwelling in the village signify the life evolution of family and also reflect the practical changes of function needs (Figure 4). Taos' dwellings have more than two kitchens in one house; they distinguish the usual kitchen and the kitchen for smoking the flying fishes. No toilet is allowed to be inside the house [2]. 

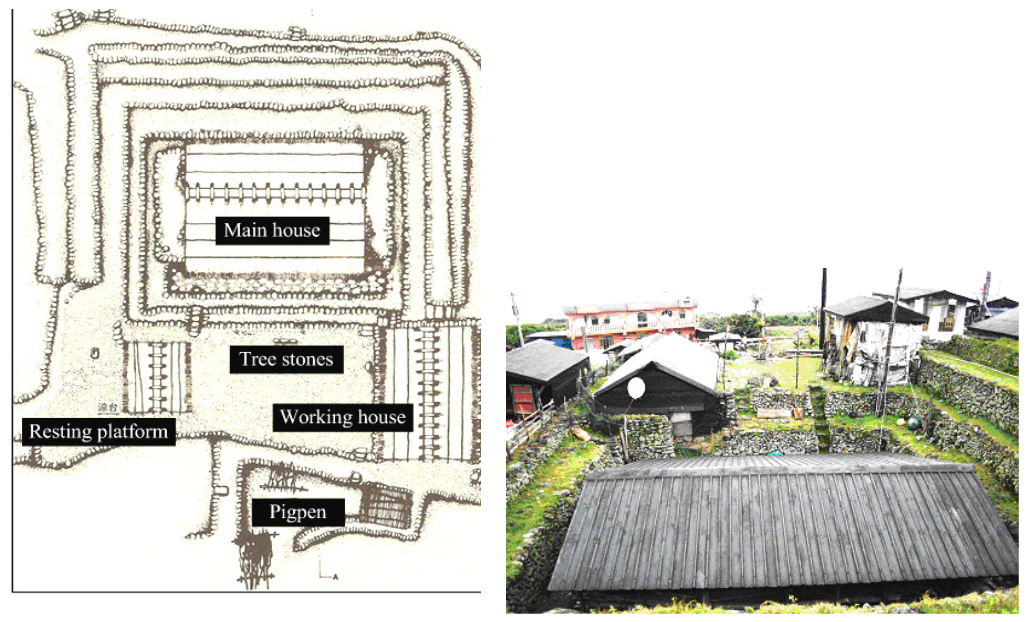

Figure 3: Disposition and photo of traditional dwelling of the Tao people $[2,3]$.

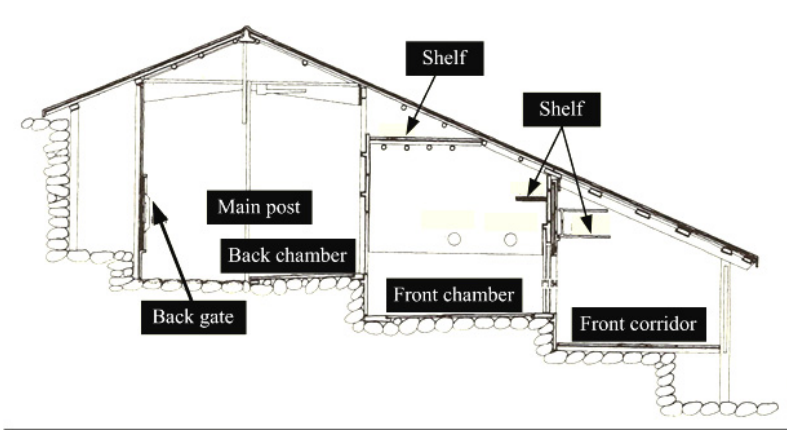

Figure 4: The configuration of the traditional subterranean dwelling [3].

\section{Recent developments and impacts}

Like many other aboriginal communities in Taiwan, this island is facing unavoidable impacts when it moves towards for a modern society. The main events consist of several stages of inappropriate dwelling projects, nuclear dump storage projects and the autonomous movement of the island. These impacts cause the distinct changes such as the total landscape of island, the unsustainable transition of human settlement and unsuitable land management.

\subsection{Storage program of nuclear waste}

In 1974, the Atomic Energy Commission of Taiwan selected the southern tip of Orchid Island as the site to build a "temporary" nuclear waste disposal facility. 
In fact, it was intended to store nuclear waste over a period of 50 years. This affair lead to anti-nuclear groups holding demonstrations in Taipei and demanding that the Taipower Company make the following commitments: to stop the expansion of the second phase of construction on the waste site; the immediate stoppage of all nuclear shipments to Orchid Island; and the complete shutdown of the storage site by 1992 .

But till now, the government cannot find an effective alternative site for storing the nuclear waste. Taipower asked the islanders to extend the storage facility for another nine years from 2002 in exchange for NT\$200 million (\$5.7 million). However, this compensation wouldn't be applied efficiently and properly to the island. The modern thinking and development logic done without taking into account the local culture and environment are imposed in various projects.

\subsection{Housing development policy}

From 1966 to 1977, the government tried to introduce a housing development plan which demolished the traditional dwellings and filled their foundations to create space for new buildings. However, these new buildings were soon demolished due to poor construction quality especially the wrong materials, namely sea sand. Moreover, the new plans of building (Figure 5) did not respect the traditional organization and contents of dwellings, destroyed also the original spirit of home for the Tao people.

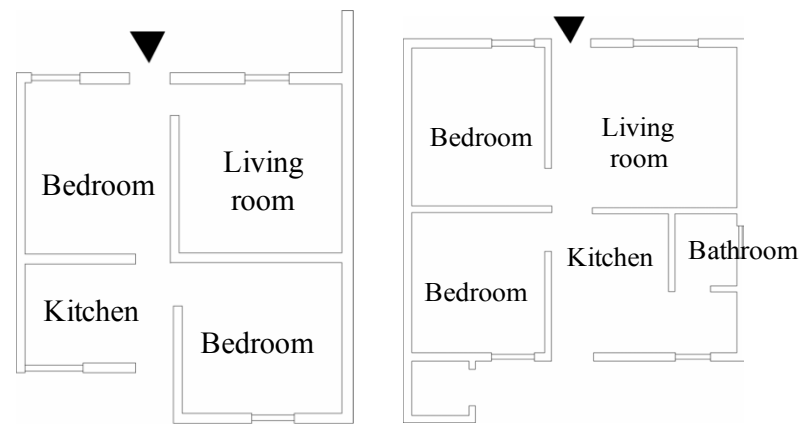

Figure 5: $\quad$ New plan of house (left: 1966-1973, right: 1975-1980).

Later on, the government changed the strategy to provide subsidies to local residents to build new houses based on their individual specifications and needs. We can observe from this stage, the modified or new dwellings showed more or less their own traditional configuration. Most of the new buildings considered having a kitchen inside, but without platform, see Figure 6. Some built additional platforms and a kitchen after constructing the main structure of the building, like Figure 7. In this stage, the people kept their old habit of having the toilet outside of their own living space. Few families remain in their old configuration of a house but without the additional platform and kitchen (Figure 8) [5]. 


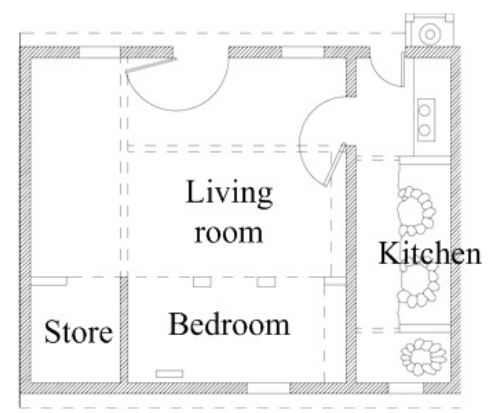

Figure 6: New building with integrated kitchen.

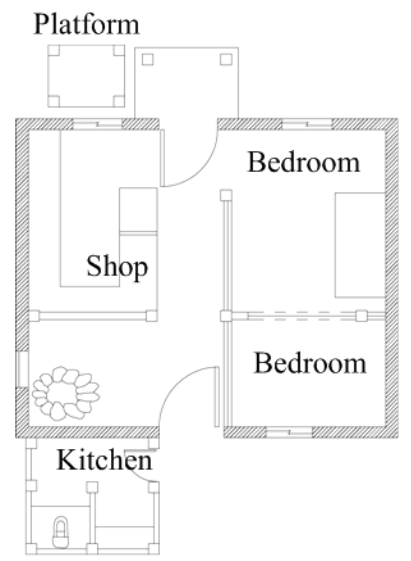

Figure 7: New building with additional platform and kitchen.

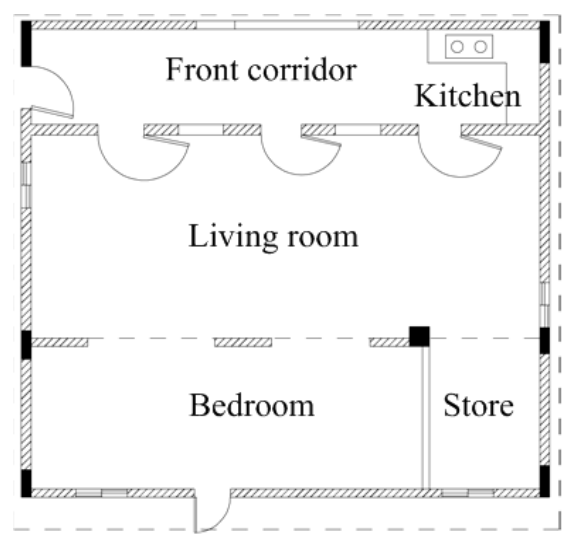

Figure 8: Traditional configuration of house.

\section{Case study of Yehyin village}

\subsection{General description}

Yehyin village is selected as a studied case because of its originality and intact situation regarding the integrity of settlement. The village extended its living space instead of demolishing the original living site. The new site situates just parallel to the original old villages. Almost each family kept their own traditional dwelling, or at least, the land inherited from their ancestors (Figure 9). The circumstance of this village allows us to discuss the possibility of both developing the new housing system and vitalizing the traditional dwellings [3]. 


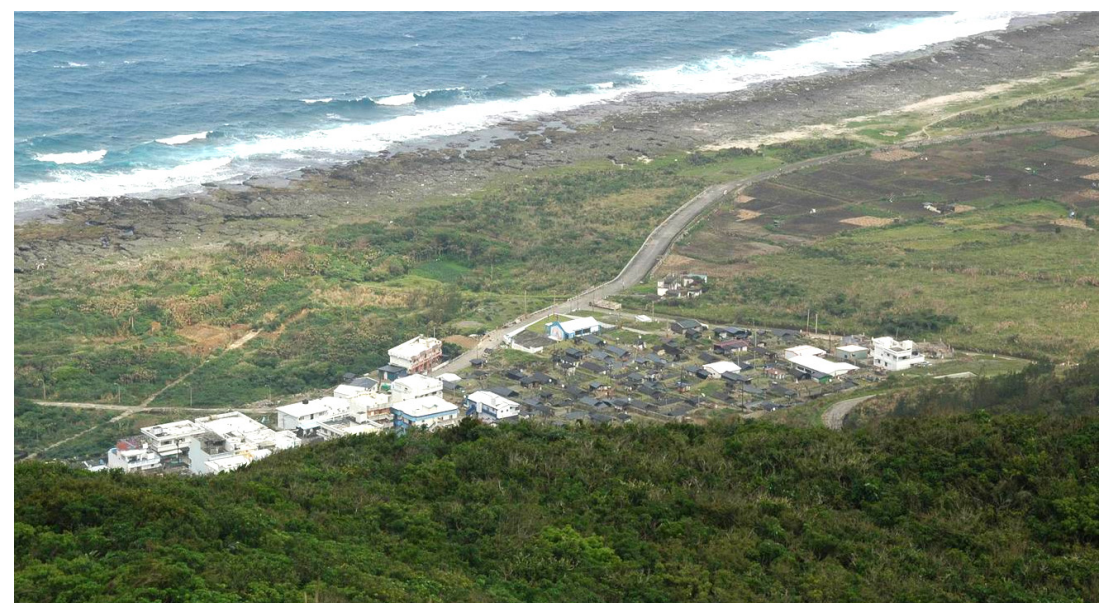

Figure 9: $\quad$ Bird's-eye view of Yehyin village.

\subsection{Characteristics of the village}

Although the villagers of Yehyin live actually in new buildings, they are still conscious on their traditional living style. The people try to restore or remodel their old dwelling using the subsidy provided by the government. In accordance with regulations, the construction material (wood) and erection method (handmade) should remain in traditional ways. The appearance of the building should be respected without distinct change. Consequently, the village can still show an extraordinary landscape with traditional texture and atmosphere of the village (Figure 10) [6].
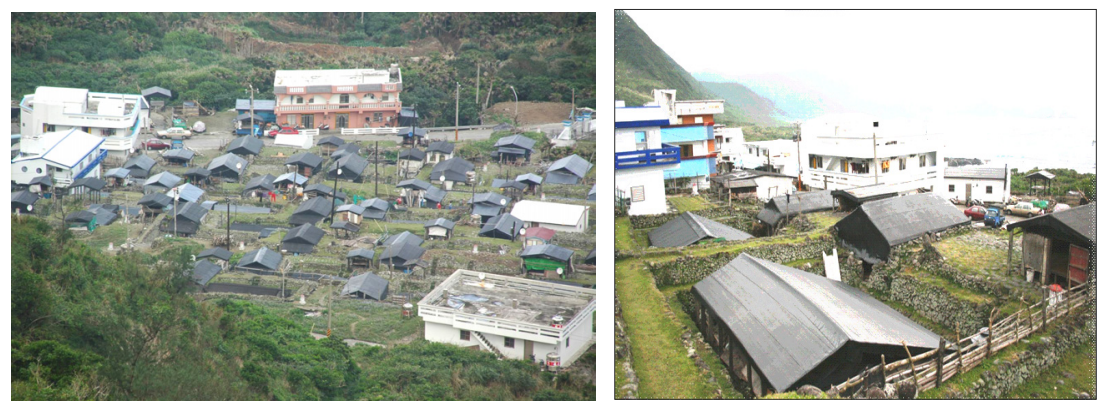

Figure 10: Traditional dwelling in Yehyin village.

We can remark on the main demands done in some restored or remodelled houses, for the kitchens and the toilet. Figure 11 and Figure 12 show two examples, in which we can find the most conventional space elements with a modern facility but without changing the original structure of the building. 


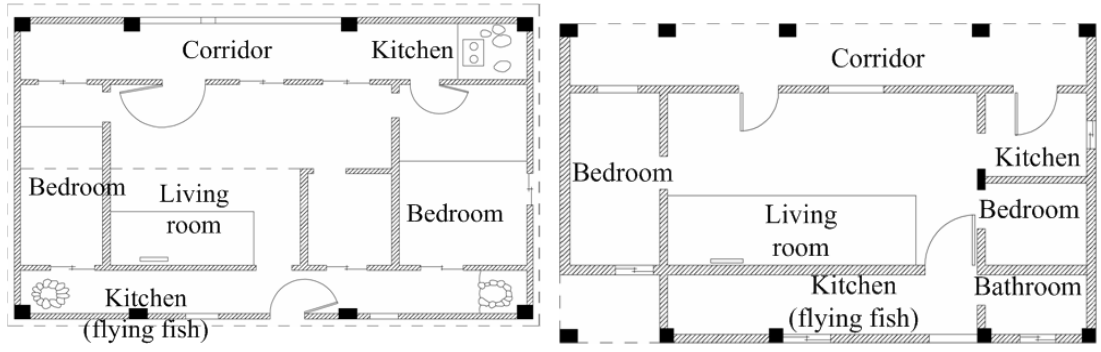

Figure 11: House restored by keeping traditional space elements.

\subsection{Development strategy for dwelling}

Compared to the other villages, Yehyin village was lucky to keep its own tradition components of settlement. In recent years, the completeness of this village becomes the most competitive when tourists are beginning to show their interest in the indigenous culture and originality of the tribe. In fact, to be a sustainable living environment on the island, both the convenience and the traditional culture should be taken care on the same level. How to define an appropriate strategy and feasible principles on dwelling development could be the most important assignment for the authority and the professionals [7].

We can conclude that several factors affect the new living space after analyzing numerous cases. They are external culture, change of living habit, modernization and climatic factors. Each factor can lead to the change of the space or the component of dwellings (Figure 12). Even for the new buildings that cannot obtain the sufficient site conditions to remain the same configurations as the traditional ones, some indispensible space element and building should not be neglected, like the platform for the quotidian use especially in summer time, and the working house which provides alternative uses for the young people and informal communication. Figure 13 shows a complete organization of a dwelling. More details of the design principles and more effective items can be established based on the different considerations for the architecture plan of new dwellings (Table 1) [3].

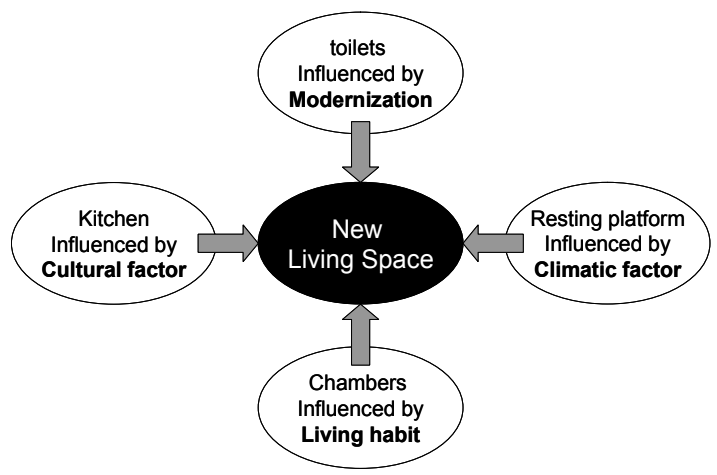

Figure 12: Factors affecting new living space of Orchid Island. 


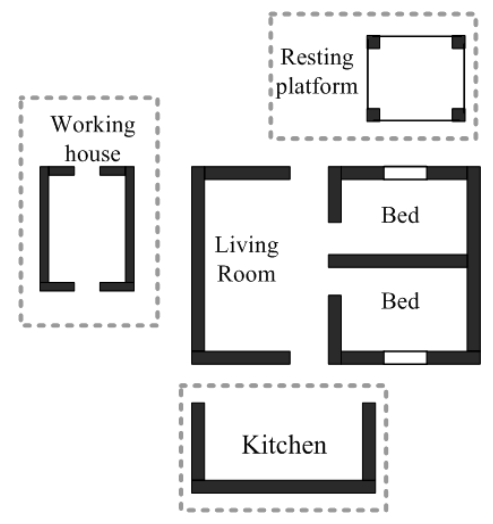

Figure 13: Modern dwelling with all traditional components.

Table 1: $\quad$ The design principle of a modern dwelling.

\begin{tabular}{|c|c|c|}
\hline Design Goal & Principles & Contents \\
\hline $\begin{array}{l}\text { Material and } \\
\text { Structure }\end{array}$ & $\begin{array}{l}\text { - Using local material } \\
\text { - Sustainable plan } \\
\text { - Appropriate building } \\
\text { type }\end{array}$ & $\begin{array}{ll} & \text { Heat insulation in roof } \\
\text { - } & \text { Simple and safety } \\
\text { structure } \\
\text { - } & \text { Flexible indoor space } \\
\text { - } & \text { Shutter and window } \\
& \text { against wind } \\
\end{array}$ \\
\hline Site & $\begin{array}{l}\text { - Natural and flexible } \\
\text { - site definition }\end{array}$ & $\begin{array}{l}\text { - Traditional boundary with } \\
\text { stone } \\
\text { - Natural topography }\end{array}$ \\
\hline $\begin{array}{l}\text { Waste water } \\
\text { and grey water }\end{array}$ & - Modern technology & $\begin{array}{ll} & \text { Establishing Septic tank } \\
\text { - } & \text { Establishing drainage } \\
& \text { system } \\
\end{array}$ \\
\hline $\begin{array}{l}\text { Transition } \\
\text { between port } \\
\text { and front court }\end{array}$ & $\begin{array}{l}\text { - Suitable outdoor } \\
\text { space }\end{array}$ & $\begin{array}{ll}- & \text { Sea facing front court } \\
- & \text { Permeable ground surface } \\
- & \text { Greening garden }\end{array}$ \\
\hline $\begin{array}{l}\text { Comprehensive } \\
\text { Dwelling }\end{array}$ & $\begin{array}{l}\text { - Taking seasonal } \\
\text { meaning into } \\
\text { consideration in } \\
\text { dwelling constitution }\end{array}$ & $\begin{array}{ll}\text { - } & \text { Space with gradation } \\
& \text { Working house becomes } \\
& \text { leisure space } \\
- & \text { Resting platform as } \\
& \text { summer shelter } \\
\text { - } & \text { Multifunctional corridor } \\
\text { - } & \text { Living room and } \\
& \text { bedrooms } \\
\text { - } & \text { Flying fish smoking room } \\
\text { - } & \text { Kitchen and stock } \\
\text { - } & \text { Laundry and bathroom } \\
\end{array}$ \\
\hline
\end{tabular}




\section{Discussion}

The original human settlement in Orchid Island inspires in us the meaning of a sustainable primitive society, where the indigenous culture, natural landscape and the tribe ethics rely on each other. Nowadays, in order to response to different external impacts, the dwelling development becomes a complicated phenomenon on the island. Various consequences can be seen in the same village and on the same sites. They are the conservation, the adaptation and the transformation of the village all at the same time. The main challenges for the Tao people will be: how to guard their own traditions without ignoring the modernization, how to utilize the modern technology without abandoning the ancient wisdom with nature and how to increase the living quality without forgetting the spirit of living culture.

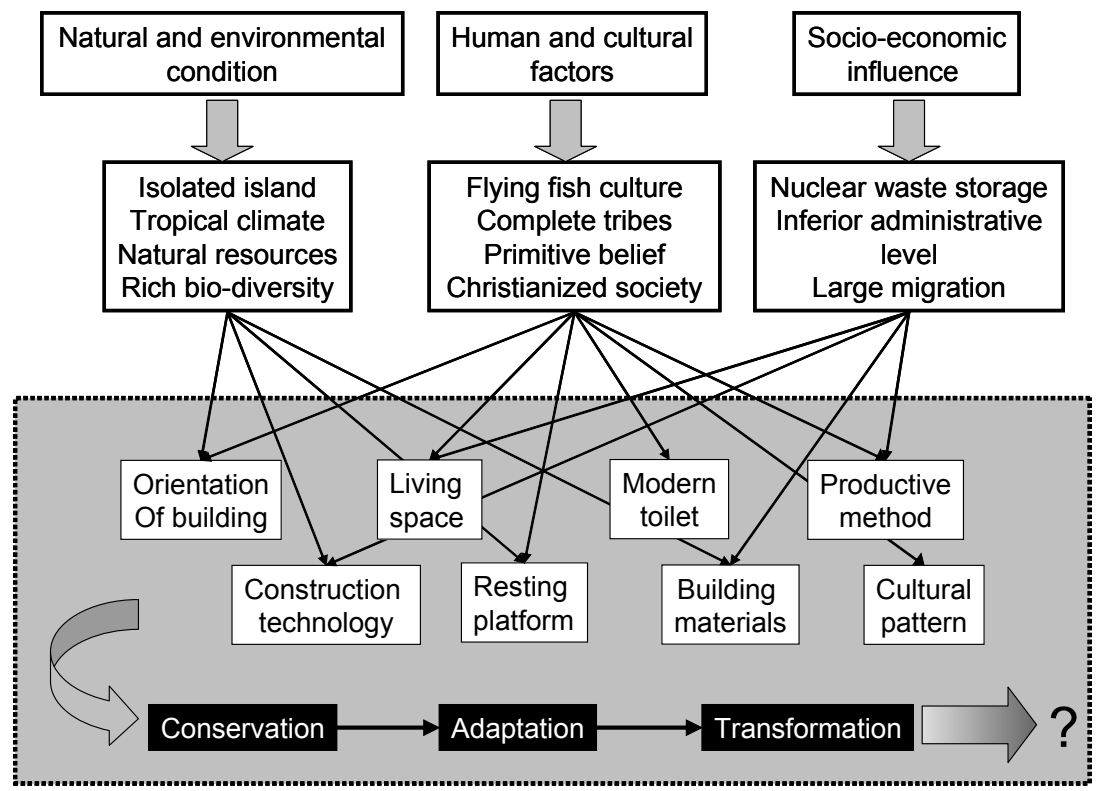

Figure 14: The main factors affecting the contents of a dwelling development.

\section{Conclusion}

Orchid Island is the most original human settlement for Taiwan that is almost intact and represents an important human culture and a unique landscape. The island can be taken as a typical sustainable milieu for aboriginal human settlement. Due to the inappropriate policy (such as the different stages of housing development project and the storage program of nuclear waste) and the socio-economic impacts, the traditional settlement is at the crossroads of compromising the different values between indigenous culture and external impacts. 
Although the traditional dwelling on the island reflects a remarkable example of vernacular architecture, the change of the space as well as of building type is however unavoidable due to the introduction and the acceptance of modern life. How to remain with the sustainable thinking and traditional intelligence, reapplying them to new generations of living space should be the most important task for the Tao people. This study describes the evolution of human settlement and housing development based on the actuality of the island and tries to propose the concept and design principles for defining a new dwelling.

\section{References}

[1] http://www.tta.gov.tw/ch/chinese6.asp

[2] H. Huang, The Transition of Yami's Living Culture, 1995, Taipei

[3] Chi-Jen Chen, Course Materials of Vernacular Architecture, 2008, National University of Kaohsiung, Taiwan

[4] http://www.gio.gov.tw/taiwan-website/5-gp/yearbook/2002/chpt02-2.htm

[5] Xi-Juan Lin, The Study on Housing Environment of Yami in Lanyu, Master thesis, 1978, National Cheng Kung University, Taiwan

[6] Zhu-Jiu Xia, Zhi-Wu Chen, The Economical Development of Taiwa ,Society Constitution of Lanyu and The Space Roll of National park, 1998, Taiwan: A Radical Quarterly in Social, Vol.1, No.4, pp.233-246

[7] Hsin-Ya Chen, A study of Environmental and Cultural Impacts of Developing Tourism to Lanyu with the Viewpoint of Sustainable Development, 2006, National Kaohsiung Normal University, Taiwan 